\title{
DEVELOPMENT OF ATTENUATED ENERGY SPECTRUMS AT X-RAY ENERGIES OF 60 KEV AND 150 KEV USING CONCRETE MANUFACTURED WITH ELECTRIC ARC FURNACE SLAG AGGREGATES \\ Davatee Maharaj $^{*}$, Abrahams Mwasha ${ }^{2}$ and Nikolay Zyuzikov ${ }^{3}$ \\ Faculty of Engineering, The University of the West Indies, Trinidad \\ ${ }^{1}$ Email: devimaha1222@ hotmail.com (*Corresponding author) \\ ${ }^{2}$ Email: Abrahams.Mwasha@sta.uwi.edu \\ ${ }^{3}$ Email: Nikolay.Zyuzikov@sta.uwi.edu
}

\begin{abstract}
This paper provides a simplified method to deduce the attenuated energy spectrum of X-ray radiation when it traverses through concrete made with $100 \%$ electric arc furnace slag aggregates. Electric arc furnace slag is a by-product of the steel making process and in this study, it was utilized as an aggregate in the concrete. The attenuation of the radiation through the concrete is attributed to possible absorption and scattering of X-ray photons. Typically, X-ray procedures are conducted within the energy settings of the X-ray machines in the range of 60 $\mathrm{keV}$ to $150 \mathrm{keV}$. As such, the lowest and the highest energy settings were considered in evaluating the degree of attenuation attained at these values. The concrete shielding partitions of thicknesses of $15 \mathrm{~cm}, 17 \mathrm{~cm}, 19 \mathrm{~cm}$ and $22 \mathrm{~cm}$ were constructed and exposed to X-ray energies of $60 \mathrm{keV}$ and $150 \mathrm{keV}$ respectively. The calculated X-ray spectrum through the concrete partitions describing the energies of the photons was compared with the spectrum incident on the concrete partition. The overall reduction of the energies of the photons is attributed to the interaction processes between the X-ray photons and the atoms as they traverse through the concrete partition.
\end{abstract}

Keywords: Attenuated, X- ray spectrum, Electric arc furnace slag, Concrete, Photons.

\section{https://doi.org/10.47412/EGXK8697}

\section{Introduction}

X-rays consist of massless, uncharged particles known as photons and when these photons come in contact with matter, they are either absorbed, scattered or penetrate through the matter without any attenuation [1]. The absorption, scattering and penetration of the photons when they come into contact with matter, depend on the extent to which the energy of the photons is reduced as they traverse through matter [2]. However, owing to the ionizing nature of X-ray radiation, exposure to this type of radiation could be harmful because it may disrupt the functioning of the living tissues [3]. As such, in recent times, due to the increased use of X-ray generating equipment in medical facilities, there is a growing concern about whether the areas where the radiation producing equipment are operated are adequately shielded to prevent the radiation from escaping to nearby areas [4].

A radiation shield forms a barrier which absorbs the photons and interacts with it so that its passage through it is blocked [5]. The process by which the energy of radiation is minimized is called attenuation and is dependent on the density of the shielding material such that a dense shielding 
material with a high atomic number is a good attenuator of X-rays [5]. A dense material with a high atomic number means there is a large number of electrons present in the material for interacting with the incoming photons [2].

Typically, lead is the common material utilized in shielding X-ray radiation. Due to the high toxicity, availability, cost and disposal problems of lead, increasing attention is being given to other materials such as high density Portland Cement Concrete (PCC) that could be utilized to shield radiation [6]. One such material is high density concrete. Aggregates occupy approximately $70 \%$ of the volume of concrete and significantly influence the density of the concrete produced. As such, the use of a concrete shield made from high density aggregates instead of normal weight aggregates can permit an overall building cost reduction by decreasing the size of the structure enclosing the shield [7].The higher the density, the smaller the thickness of concrete required to adequately reduce the energy of the radiation.

However, in recent years, the extraction and availability of natural aggregates for concrete production has become a cause of concern due to the depletion of natural quarries and the emissions from the extraction processes [8]. The consistent exploitation of natural material for concrete production poses a serious challenge to the sustainability of the environment [9]. Therefore, the possibility of natural aggregate replacement with recycled material could result in energy savings and natural resource conservation. In this study, the recycled material considered in concrete production is electric arc furnace slag.

Even though $[10,11,12,13,14,15,16]$ examined the effect of electric arc furnace slag aggregates on the physical and mechanical properties of concrete, the behaviour of the concrete made with $100 \%$ electric arc furnace slag aggregates when exposed to X-ray radiation was not evaluated.

In this paper, the behaviour of concrete manufactured with $100 \%$ electric arc furnace slag aggregates when exposed to different $X$-ray energies was analyzed by deducing the absorption and the scattering of the X-rays photons as they traverse through the concrete material.

\section{Materials and Methods}

\subsection{Materials and Sample Preparation}

The materials used for the production of concrete were:

1. Cement: Blended cement was utilized in the concrete mixtures and was obtained from a local cement factory (Trinidad Cement Limited).

2. Aggregates: The aggregates used to formulate the concrete mixtures were electric arc furnace slag aggregates. Electric arc furnace slag is a by-product from the steel making process and is typically left in stockpiles at the production site when it is produced. The electric arc furnace slag aggregates were obtained from the stockpile at the Arcelor Mittal Steel Factory. The aggregates were utilized using a fine to coarse aggregate ratio of 90 to 10.

3. Silica Fume: This is a highly effective pozzolan in powdered form of extreme fineness with diameter of order ( 0.1 microns) and consists primarily of amorphous (non-crystalline) silicon dioxide [6].These particles are very small (finer than cement particles), smooth and spherical in shape.

\subsection{Experimental Procedure}

(i). Rotary drum mixer: This was used to mix the concrete components together 
(ii). X-ray source: X-ray measurements were made at energies of $60 \mathrm{keV}$ and $150 \mathrm{keV}$ respectively from the machine. The proportions of the materials used for the concrete mixture are described in Table 1. The thicknesses of the concrete samples utilized for the X-ray radiation attenuation test were extracted from [18]. Typically, X-ray procedures are conducted within the energy settings of

\begin{tabular}{|c|l|l|l|l|l|l|}
\hline $\begin{array}{l}\text { Thickness } \\
(\mathrm{cm})\end{array}$ & $\begin{array}{l}\text { Mass } \\
\text { of concrete } \\
(\mathrm{kg})\end{array}$ & $\begin{array}{l}\text { Mass of } \\
\text { fine } \\
\text { aggregate } \\
(\mathrm{kg})\end{array}$ & $\begin{array}{l}\text { Mass of coarse } \\
\text { aggregate } \\
(\mathrm{kg})\end{array}$ & $\begin{array}{l}\text { Mass } \\
\text { of water } \\
(\mathrm{kg})\end{array}$ & $\begin{array}{l}\text { Mass } \\
\text { of } \\
\text { cement } \\
(\mathrm{kg})\end{array}$ & $\begin{array}{l}\text { Mass of } \\
\text { silica } \\
\text { fume } \\
(\mathrm{kg})\end{array}$ \\
\hline 15 & 274 & 170 & 19 & 22 & 57 & 6 \\
\hline 17 & 311 & 193 & 21 & 25 & 64 & 7 \\
\hline 19 & 348 & 216 & 24 & 28 & 72 & 8 \\
\hline 22 & 402 & 250 & 28 & 32 & 89 & 3 \\
\hline
\end{tabular}

the X-ray machines in the range of $60 \mathrm{keV}$ to $150 \mathrm{keV}$. As such, the lowest and the highest energy settings were considered in evaluating the degree of attenuation attained at these values. The concrete shielding partitions of thicknesses of $15 \mathrm{~cm}, 17 \mathrm{~cm}, 19 \mathrm{~cm}$ and $22 \mathrm{~cm}$ were constructed and exposed to X-ray energies of $60 \mathrm{keV}$ and $150 \mathrm{keV}$ respectively. Using a water to cement ratio of 0.35 , an aggregate to cement ratio of 3 , the volume of the concrete mixture was $0.03 \mathrm{~m}^{3}$; the proportions of the materials required for the concrete mixtures were determined. The proportions of the materials are illustrated in Table 1.

Table 4: Mix proportions of the materials used in the concrete mixture

The materials were placed in a rotary drum mixer in the following sequence:

1. The coarse and fine electric arc furnace slag aggregates, cement and silica fume which were allowed to mix for approximately 5 minutes.

2. The water was added after the mixer was started and all the materials were allowed to mix thoroughly for 7 minutes.

3. The concrete mixture was then placed in the molds designed to accommodate the concrete specimens.

4. Each layer of the molds was consolidated using a vibrating table. The concrete samples were left in the laboratory at room temperature for twenty four hours before they were placed in a water basin and kept for a twenty eight day period.

5. After a twenty eight day period, the concrete specimens were removed from the water and left in the sun until completely dried.

6. The hardened concrete specimens were cut into thicknesses of $15 \mathrm{~cm}, 17 \mathrm{~cm}, 19 \mathrm{~cm}$ and $22 \mathrm{~cm}$.

\subsection{Radiation Attenuation Test}

The behaviour of the concrete made with electric arc furnace slag aggregates when exposed to the $\mathrm{X}$-rays was conducted using the arrangement as shown in Fig.1.The radiation source which was utilized comprised of X-ray radiation using selected energy values of $60 \mathrm{keV}$ and $150 \mathrm{keV}$. The 
concrete test samples of thicknesses $15 \mathrm{~cm}, 17 \mathrm{~cm}, 19 \mathrm{~cm}$ and $22 \mathrm{~cm}$ were arranged in front of a collimated beam generated from an X-ray source. The measurements were conducted using a 20 minute counting time for each sample. An illustration of the experimental arrangement is displayed in Fig. 1.

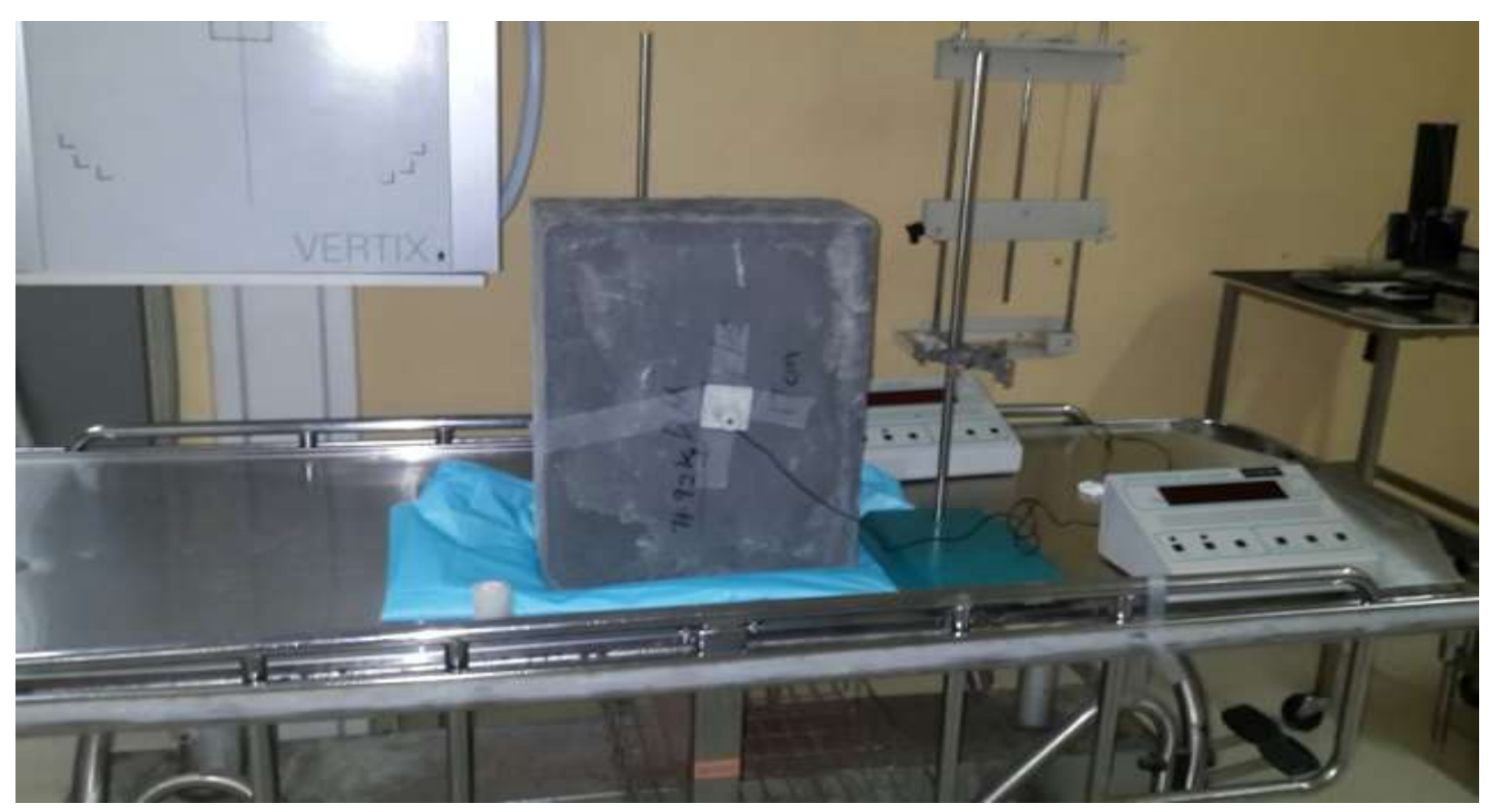

Figure 1: Arrangement of the concrete partition for the X-ray radiation test

According to [17], the mean free path is the average distance travelled by the photon between successive interactions with the electrons of the atoms and is described using Eq. (1):

$$
\text { Mean free path }=\frac{1}{\mu}
$$

where $\mu$ is the linear attenuation coefficient.

Eq. (1) shows that at higher linear attenuation coefficient values, the mean free path distance is small as compared to lower linear attenuation coefficient values in which the mean free path distance is higher. As such, the value of the mean free path primarily depends on the energy of the photon such that a photon having at a higher energy and a lower linear attenuation coefficient will move a greater distance before interacting with the electrons of the atoms present in the shielding material.

\section{Results and Discussion}

According to [17], each of X-ray energy has a characteristic spectrum associated with it and depends on the voltage at which the X-ray tube is set. These values are the equivalent to energy 
values in electron-volts $(\mathrm{eV})$ because when the tube is set at these voltage values, the electrons in the X-ray tube are accelerated through these voltage values within the X-ray tube. The energy spectrum generated from a typical X-ray tube is illustrated in Fig. 2.

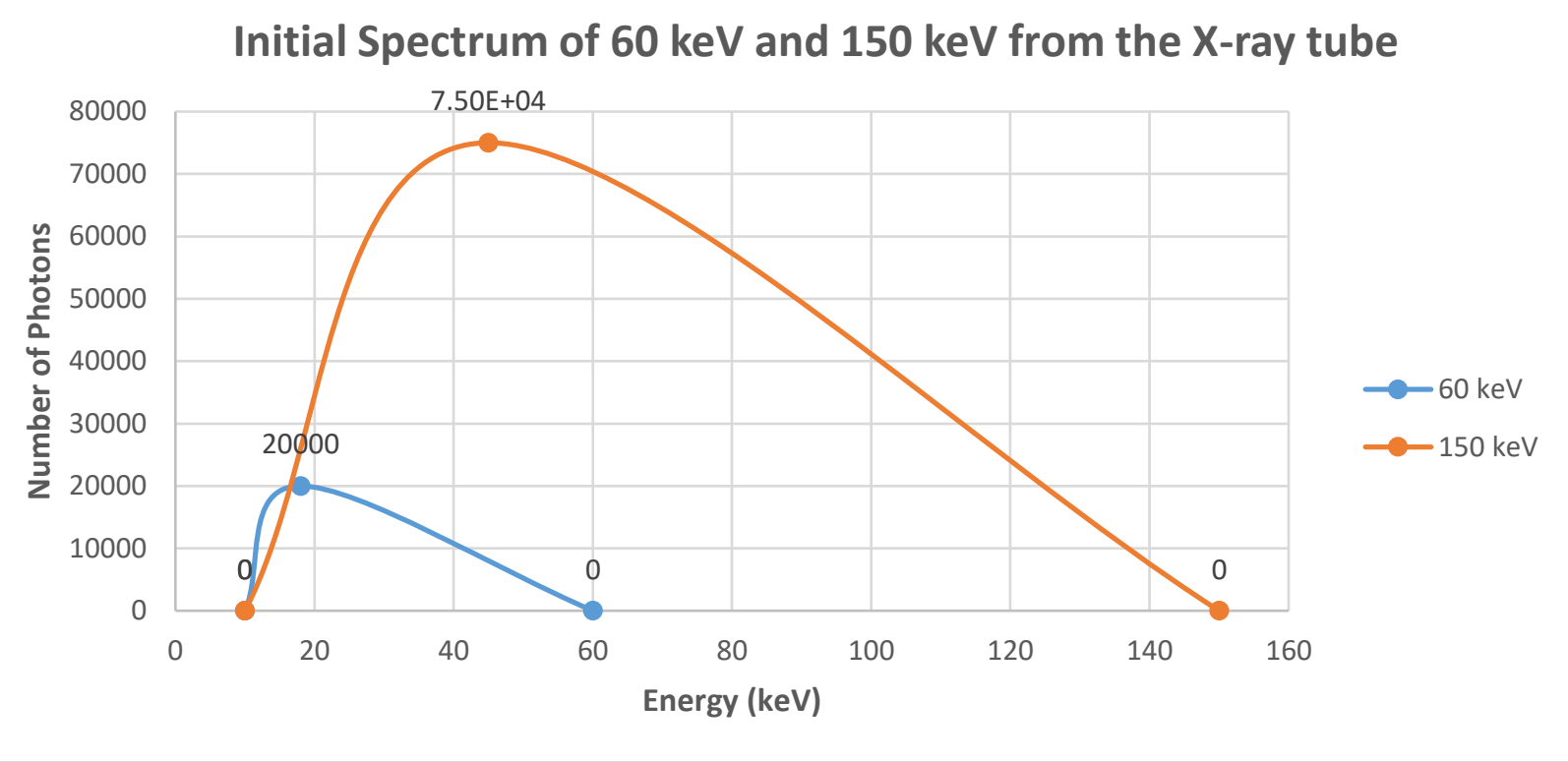

Figure 2: X-ray spectrum from an X-ray tube showing the number of photons against energy of $60 \mathrm{keV}$ and $150 \mathrm{keV}$ for a typical X-ray machine

Fig. 2 describes the work done by [17], who formulated the spectrum by considering that each tube voltage generates photons at a range of different energies and a specific number of photons is produced at each energy value. This explains that at each $\mathrm{X}$ - ray tube voltage value, photons are released with a range of different energies. It is also estimated that the highest energy of the photons leaving the X-ray tube is called the effective energy and is represented by the peak of each graph [17].Therefore, at each of these energy values, a specific number of photons is produced from the X-ray tube. The effective energy is approximated at $30 \%$ of each energy value which is equivalent to the voltage at which the tube is set [24]. As shown in Fig. 2; for all energies used, at $10 \mathrm{kV}$, the number of photons is zero. Using the peak energy values shown in Fig. 4, the number of photons at the effective energy values are stated in Table 2.

Table 5: Number of photons at the effective energy values [17]

\begin{tabular}{|l|l|l|}
\hline $\begin{array}{l}\text { Energy } \\
\text { Value }(\mathrm{kV})\end{array}$ & $\begin{array}{l}\text { Effective Energy: } \\
(\mathrm{kV})=30 \% \text { (Energy Value) }\end{array}$ & $\begin{array}{l}\text { Number of Photons at } \\
\text { Effective Energy Value }\end{array}$ \\
\hline 60.0 & 24.0 & $2.0 \times 10^{4}$ \\
\hline 150.0 & 50.0 & $7.5 \times 10^{4}$ \\
\hline
\end{tabular}

The X-ray spectrum illustrated in Fig. 3 and the values stated in Table 2 show the variation of the number of the number of photons with the energy from a typical X-ray tube. This spectrum describes the range of energies of the photons incident on the concrete block before they are attenuated. Due to the attenuation of the energy of the photons as they traverse through the block, the photons will lose energy. This will cause the spectrum to change such that the effective energy will be lower in the concrete block. According to [1], if the energy of the X-ray photon before it is 
scattered is $E_{0}$ and the energy of the $X$-ray photon after scattering is $E_{f . ;}$ then $E_{0}$ and $E_{f}$ are related by Eq. (2):

$$
\frac{1}{E_{f}}-\frac{1}{E_{0}}=\frac{1}{m c^{2}}(1-\cos \theta)
$$

- $\mathrm{E}_{\mathrm{f}}$ is the energy of the photon after it interacts with the electron of the atom

- $\mathrm{E}_{0}$ is the energy of the photon before it interacts with the electron of the atom

- $\mathrm{mc}^{2}$ is the rest mass energy of the electron of the atom and has a value $511 \mathrm{MeV}$

- $\theta$ is the scattered or deviated angle of the photon after interacting with an electron of an atom

\subsection{Determination of the Attenuated Energy of the Photons after Moving Through the Mean Free Path Distance}

Photons travel a certain distance known as the mean free path distance before interacting with the electrons of atoms which causes their respective energies to be reduced [1]. At the average values of the distance travelled by the photons for each thickness given; the attenuated energy of the photons after moving through this distance was estimated using the following steps:

1. The values of the linear attenuation coefficient at the energies of $60 \mathrm{keV}$ and $150 \mathrm{keV}$ were extracted from the mass attenuation coefficients using the data provided by [20].

2. The determination of the mean free path distance at each energy value of $60 \mathrm{keV}$ and $150 \mathrm{keV}$ using equation (1).

3. The estimation of the energy value at each mean free path distance was determined using Eq. (2)

4. The corresponding number of scattered photons at the energy value of each mean free path distance was calculated by reading off the values of the number of photons at the respective energies from the initial X-ray spectrum illustrated in Fig. 3.

Using the average thickness of the concrete for the energies of $60 \mathrm{keV}$ and $150 \mathrm{keV}$, the calculation of each mean free path at the respective energies was determined. The number of scattered photons at the respective attenuated energy values is illustrated in Fig. 3 and Fig. 4 respectively. 
Number of Scattered X-ray photons at energy $60 \mathrm{keV}$

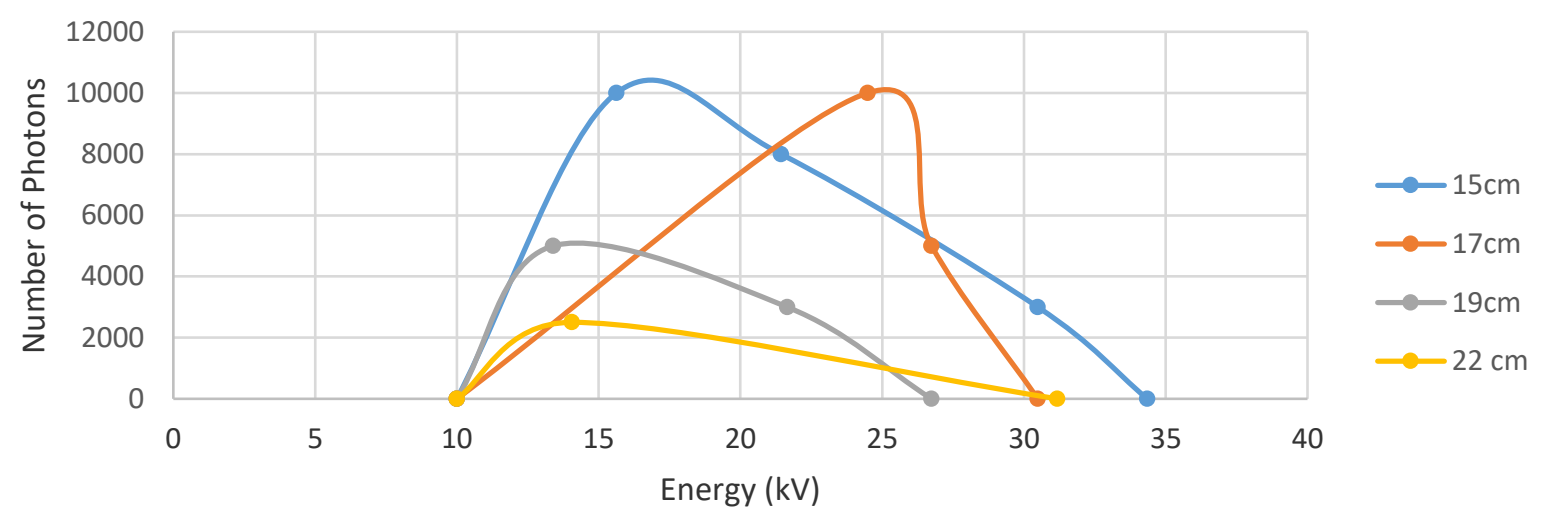

Figure 3: Attenuated energy spectrum of $60 \mathrm{keV}$

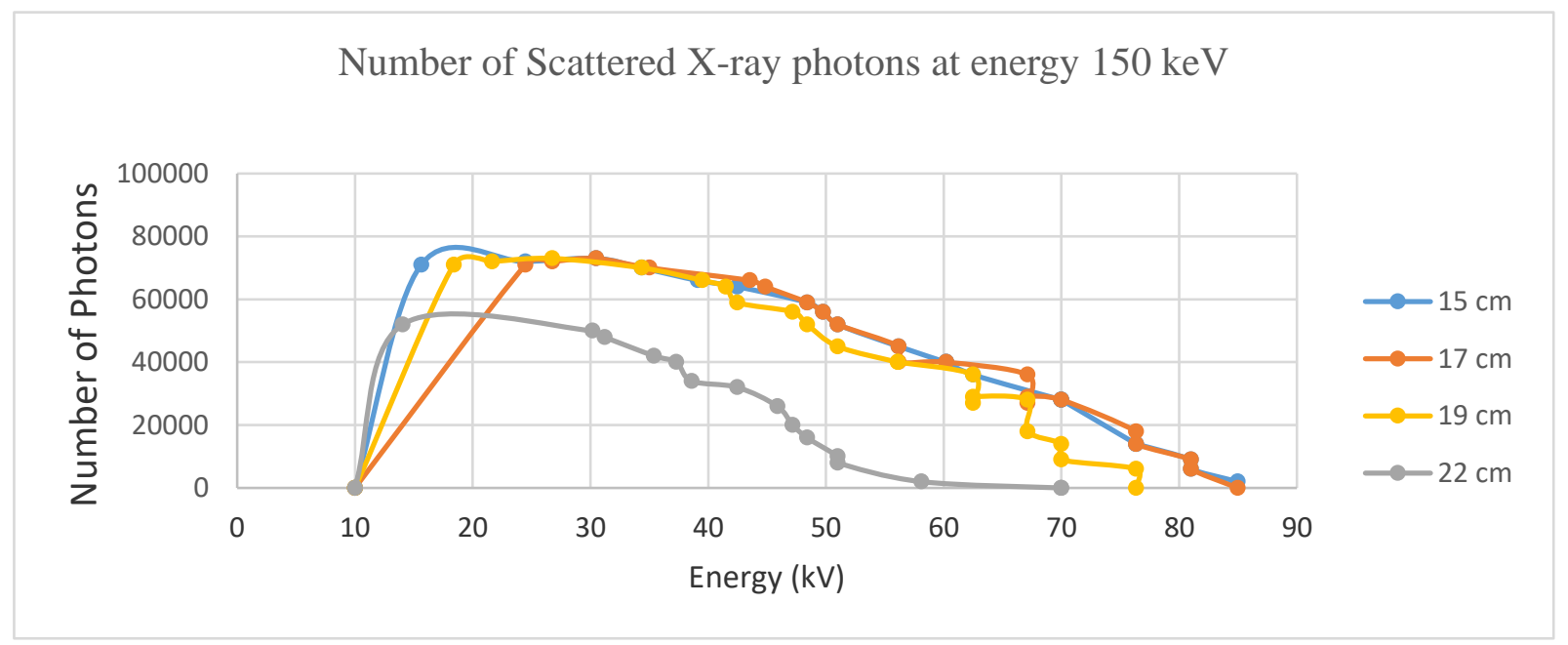

Figure 4: Attenuated energy spectrum of $150 \mathrm{keV}$

Table 3: Number of Photons at the effective energy value of $24 \mathrm{keV}$

\begin{tabular}{|c|c|c|}
\hline $\begin{array}{c}\text { Thickness of Concrete } \\
\text { Partition }(\mathrm{cm})\end{array}$ & $\begin{array}{c}\text { Number of Scattered X -ray } \\
\text { Photons }\end{array}$ & $\begin{array}{c}\text { Factor by which the number } \\
\text { of } \\
\text { X-ray photons decreased }\end{array}$ \\
\hline 15 & 60,000 & 0.20 \\
\hline 17 & 60.000 & 0.20 \\
\hline 19 & 50.000 & 0.33 \\
\hline 22 & 10,000 & 0.87 \\
\hline
\end{tabular}




\begin{tabular}{|c|c|c|}
\hline $\begin{array}{c}\text { Thickness of Concrete } \\
\text { Partition }(\mathrm{cm})\end{array}$ & $\begin{array}{c}\text { Number of Scattered X -ray } \\
\text { Photons }\end{array}$ & $\begin{array}{c}\text { Factor by which the number of } \\
\text { X-ray photons decreased }\end{array}$ \\
\hline 15 & 10,000 & 0.35 \\
\hline 17 & 7,000 & 0.70 \\
\hline 19 & 2,000 & 0.90 \\
\hline 22 & 1,800 & 0.95 \\
\hline
\end{tabular}

Table 4: Number of Photons at the effective energy value of $50 \mathrm{keV}$.

Table 3 and Table 4 illustrate the number of the scattered X-ray photons which corresponds to the effective number of photons which are generated at the energy of $60 \mathrm{keV}$. From Table 3 and Table 4 , it is evident that as the thickness of the concrete samples increased, the number of photons also decreased.

\section{Conclusion}

The findings from the experiment provide a quantitative measure of the reduction of the radiation as it traverses through the concrete. Having observed the initial X-ray spectrum incident on the concrete block at the energy values of $60 \mathrm{keV}$ and $150 \mathrm{keV}$, the initial spectrum has a higher number of photons than the absorption and scattering spectrums respectively. As such, it can be deduced that the energies were attenuated through the concrete block. Based on the degree of attenuation achieved due to the absorption and scattering of the photons; it can be inferred that concrete made with electric arc furnace slag aggregates significantly contributes to the reduction of the number of photons passing through it. As such, it is evident that concrete formulated using electric arc furnace slag aggregates is an effective material to minimize the energy of the photons as they pass through it.

\section{References}

[1]J.Parks.2001.Attenuation of "Lecture Nadiation. Notes." www.phys.utk.edu/labs/modphys/Attenuation Radiation.pdf.

[2] M. H. Kharita, M. Takeyeddin, M. Alnassar, S. Yousef (2008). Development of Special Radiation Shielding Concretes using Natural Local Materials and Evaluation of their Shielding Characteriastics. Annals of Nuclear Energy. Elsevier Publications. 33-36.

[3] NCRP 2004. Structural Shielding Design for Medical X-Ray Imaging Facilities. Report no. 147. Bethesda: National Council on Radiation Protection.

[4] I. Akkurt, H. Akyildirim, B. Mavi, S. Kilincarslan, C. Basyigit. 2010. "Radiation Shielding of Concrete Containing Zeolite.” Radiation Measurements 45(7): 827 - 830.

[5] ICRP. 2007. Recommendations of the International Commission on Radiological Protection. ICRP Publication 103. Annals of the ICRP. 37. 2-4.

[6] D. S. Ochbelagh-Rezaei, H. Azimkhani,G. Mosavinejad. 2012. "Investigation of Gamma-Ray Shielding Properties of Concrete Containing Different Percentages of Lead." Applied Radiation and Isotopes 70(10): 2282-2286.

[7] T. E. Northup.1963. "High Density Slag Concrete.” Master's thesis. University of Tennessee, Tennessee. 
[8] S. Ismail, K.W. Hoe, M. Ramli. 2013. "Sustainable Aggregates: The Potential and Challenge for Natural Resources Conservation." Procedia-Social and Behavioral Sciences 101: 100 - 109. [9] O. Zimbili, W. Salim, M. Ndambuki. 2014. "A Review on the Usage of Ceramic Wastes in Concrete Production." International Journal of Civil, Architectural, Structural and Construction Engineering 8 (1): 91-95.

[10] M. Chini, R. Alizadeh, P. Ghods, M. Hoseini, S. Montazer, M. Shekarchi. 2003. "Utilization of Electric Arc Furnace Slag as Aggregates in Concrete Environmental Issue." 6th CANMET/ACI International Conference on Recent Advances in Concrete Technology, 9-11 June, 2006, 451-464. Bucharest, Romania.

[11] M. Rojas, S. Rojas. 2004. "Chemical Assessment of the Electric Arc Furnace Slag as Construction Material." Cement and Concrete Research 34 (10): 1881 - 1888.

[12] J. M. Manso, J.A. Polanco, M. Losanez, and J.J. Gonzalez. 2006. "Durability of Concrete made with Electric Arc Furnace Slag As Aggregate." Cement and Concrete Composites 28 (3): 528-534.

[13] H. Qasrawi, F. Shalabi, I. Asi. 2009. "Use of low CaO Unprocessed Steel Slag in Concrete as Fine Aggregate." Construction and Building Materials 23 (2): 1118-1125.

[14] I. S. Abu-Eishah, Amr S. El-Dieb, M. S. Bedir. 2012. "Performance of Concrete Mixtures Made with Electric Arc Furnace (EAF) Steel Slag Aggregate Produced in the Arabian Gulf Region." Construction and Building Materials 34: 249-256.

[15] C. Pellegrino, P. Cavagnis, F. Faleschini, K. Brunelli. 2012. "Properties of Concrete with Black/Oxidising Electric Arc Furnace Slag." Cement \& Concrete Composites 37 (30): 283 - 303.

[16] S. Sorlini, A. Sanzeni, L. Rondi. 2012. "Re-Use of Steel Slag in Bituminous Paving Mixtures." Journal of Hazardous Materials 21 (10): 84 - 91.

[17] Sprawls Educational Foundation. 2013. The Physical Principles of Medical Imaging. Atlanta, GA:Medical Physics Publishing. Accessed November 1, 2017. http://www.sprawls.org/resources/ppmi2.

[18] J. Williams, D. Sutton. 2005. "Factors for Calculating the Attenuation of Barium Plaster." British Journal of Radiology 78 (965): 1061-1065.

[19] BIR (British Institute of Radiology). 2000. Radiation Shielding for Diagnostic X-rays, Report of a Joint BIR/IPEM Working Party. London: BIR.I

[20] J.H. Hubbell, S.M. Seltzer. 1996. "Tables of X-ray Mass Attenuation Coefficients and Mass Energy- Absorption Coefficients from $1 \mathrm{keV}$ to $20 \mathrm{MeV}$ for Elements Z=1 to 92 and 48 Additional Substances of Dosimetric Interest.” Accessed July 25, 2014. http://physics.nist.gov/PhysRefData/XrayMassCoef/cover.html 